\title{
A Wii too stretched? The ECJ extends to game consoles the protection of DRM- on tough conditions.
}

\author{
Marcella Favale
}

E.I.P.R. 2015, 37(2), 101-106

Subject: Intellectual property. Other related subjects: European Union. Information technology. Media and entertainment

Keywords: Anti-copying devices; Computer games; Copyright circumvention devices; EU law; Software

Abstract: Analyses the European Court of Justice ruling in Nintendo Co Ltd v PC Box Srl (C355/12) on whether the protections for technological protection measures (TPMs) under Directive 2001/29 art. 6 extended to devices in games consoles that prevented users from playing other manufacturers' games. Assesses how art. 6 should be applied to devices that circumvented TPMs but also served other commercial purposes. Considers whether videogames fell within the scope of Directive 2009/24 (Software Directive).

\section{Introduction}

On the $23^{\text {rd }}$ of January the European Court of Justice issued its first ruling on the protection of technological protection measures. ${ }^{1}$ This protection is provided for "digital locks" by the InfoSoc Directive 29/2001/EC (hereinafter, the Copyright Directive) ${ }^{2}$, which enjoins to "provide adequate legal protection against the circumvention of any effective technological measures, which the person concerned carries out in the knowledge, or with reasonable grounds to know, that he or she is pursuing that objective. ${ }^{\prime \prime 3}$ All EU Member States have implemented the protection of technological protection measures, ${ }^{4}$ as required by Article 6 of the Directive.

The reference for a preliminary ruling was submitted to the ECJ by the Milan District Court (Tribunale di Milano), which was called to rule on a case featuring Nintendo Co. Ltd (and others) against the Tuscan company PC Box Srl (and other). ${ }^{5}$ The case concerned the sale of "mod Chips" and "game copiers" over the Internet. This equipment is able to allow games not produced or licensed by Nintendo to be played on Nintendo consoles. In particular, the devices in question referred to the

\footnotetext{
${ }^{1}$ Case C-355/12 - Nintendo and Others (not yet published on ECR).

${ }^{2}$ Directive 2001/29 on the harmonisation of certain aspects of copyright and related rights in the information society [2001] OJ L167/10.

${ }^{3}$ Ibid, Article 6.1

${ }^{4}$ M. Favale, 'Fine-Tuning European Copyright Law to Strike A Balance Between the Rights of Owners and Users', 33(5) European Law Review (2008) 687-708 at 700.

${ }^{5}$ Case C-355/12 Nintendo of Europe GmbH. v. PC Box Srl, 9Net Sr (Not yet published on ECR).
} 
"DS" consoles and "Wii" consoles, manufactured by Nintendo. The case is not the first of this kind. Nintendo has been engaged in a defensive battle against the DRM implemented on its consoles for years. So far, always with success. ${ }^{6}$

\section{The first question}

The wording that the first questions of the Tribunale di Milano asked to the European judges seems to give away the answers that the Italian judges expected:

Must Article 6 of Directive 2001/29/EC be interpreted, including in the light of recital 48 in the preamble thereto, as meaning that the protection of technological protection measures attaching to copyright-protected works or other subject matter may also extend to a system, produced and marketed by the same undertaking, in which a device is installed in the hardware which is capable of recognising on a separate housing mechanism containing the protected works (videogames produced by the same undertaking as well as by third parties, proprietors of the protected works) a recognition code, in the absence of which the works in question cannot be visualised or used in conjunction with that system, the equipment in question thus incorporating a system which is not interoperable with complementary equipment or products other than those of the undertaking which produces the system itself?

In essence (and put it more simply): may TPM protection extend to a system including a device installed in the hardware, although this makes the device not interoperable with non-proprietary products?

To our reading, the key words in the question (which we have emphasised) convey the feelings of the writers in the following way: they used the word "extend" instead of, for example, "apply", because they are aware that TPMs are normally implemented on a digital product or a digital carrier hosting a digital product (such as for example an optical disk), and applying the same protection to products other than these, in particular "hardware" devices, would imply an extension of this protection. Here, the Italian judge seems to show some concerns over the possibility of this extension, which is also confirmed by the last part of the question: "Do we have to extend the protection even though this device is not interoperable with products that are not produced by the same undertaking?" they seem to ask.

To this first question the Court gives the following reading:

By its questions, which it is appropriate to examine together, the referring court asks, in essence, in the first place, whether Directive 2001/29 must be interpreted as meaning that the concept of an 'effective technological measure', for the purposes of Article 6(3) of that directive, is capable of covering technological measures comprising, principally, equipping not only the housing system containing the protected work, such as the videogame, with a recognition device in order to protect it

\footnotetext{
${ }^{6}$ Nintendo Co Ltd v Playables Ltd Chancery Division, 28 July 2010 [2010] E.C.D.R. 14 [2010] F.S.R. 36 [2011] Bus. L.R. D89; Nintendo Co Ltd v Console PC Com Ltd Chancery Division, 19 April 2011 [2011] EWHC 1458 (Ch); I ZR 124/11 Nintendo v SR Tronic Munich High Court (LG München I - Urteil vom 14. Oktober 2009 210 22196/08 MMR 2010, 341) (OLG München - Urteil vom 9. Juni 2011 - 6 U 5037/09); Atari Games Corp. v. Nintendo of America Inc. U.S. Court of Appeals, Federal Circuit September 10,1992, 975 F.2d 832, 24 USPQ2d 1015.
} 
against acts which are not authorised by the holder of any copyright, but also portable equipment or consoles intended to ensure access to those games and their use. 7

It is interesting that the judges felt the need to reformulate the question, to dispel every concern from it, and to take it down to its bare bones: Is the directive "capable" of protecting TPMs applied to "portable equipment or console" (that is, hardware)?

However, the stark clarity of the question is lightly clouded by the addition of the adverb "principally" at a given point in the sentence. The adverb is repeated in the formulation of the Operational part of the Judgement, and it is therefore of some consequence. Does it mean that devices consisting in software and hardware on which TPMs are applied are "capable" of obtaining protection from the Directive only if they are principally implemented on both software and hardware? Should this suggest that if the principal implementation of the TPMs is either on the software or the hardware, and the implementation on the other piece of device is only accessory, they are not capable of enjoying protection? The Court sheds no further light on this point.

The reading of the first question from the Milan District Tribunal by the Advocate General Sharpston is somewhat more sophisticated than the reading by the Court:

As I understand it, the first question comprises two parts. First, do 'technological measures' within the meaning of Article 6 of Directive 2001/29 include not only those which are physically linked to the copyright material itself (here, by incorporation in the cartridges or DVDs on which the games are recorded) but also those which are physically linked to devices required in order to use or enjoy that material (here, by incorporation in the consoles on which the games are played)? Second, do such measures qualify for the protection to be provided pursuant to that provision where (or even if) their effect is not merely to restrict unauthorised reproduction of the copyright material but also to preclude any use of that material with other devices or of other material with those devices? ${ }^{8}$

Thus, the first part of the question is essentially the same: Can TPMs be implemented on hardware? However, showing greater sensitivity than the Court, AG Sharpston perceived the concerns of the Italian judges and wondered whether TPMs should enjoy protection also when, or even if, they preclude legitimate behaviours of the user.

Interestingly, neither the Court nor the AG makes reference to the lack of interoperability mentioned by the Court of Milan. For example, on this point a reference to recital 54 of the Copyright Directive would not have been out of place. ${ }^{9}$ AG Sharpston has somewhat embedded the concept of interoperability within the distinction between unauthorized reproduction of the copyright material and any other (assumedly, legitimate) use, whereas the Court has embedded it in the proportionality test which answers the second question submitted by the District Court. Any of them has explicitly discussed this issue.

\footnotetext{
${ }^{7}$ Case C-355/12, Judgement, 19.

${ }^{8}$ Case C-355/12 Opinion, 40.

${ }^{9}$ Copyright Directive, Recital 54: “[...] In an increasingly networked environment, differences between technological measures could lead to an incompatibility of systems within the Community. Compatibility and interoperability of the different systems should be encouraged. It would be highly desirable to encourage the development of global systems."
} 
On the contrary, the European judges provide a rather concise answer to the first question, articulated in two points: 1 ) "there is nothing in that directive [the Copyright Directive] to suggest that Article 6(3) thereof does not refer to technological measures such as those at issue in the main proceedings, which are partly incorporated in the physical housing systems of games and partly in consoles which requires interaction between them." ${ }^{10}$ And 2) TPMs in the directive are defined broadly.

This approach of the Court seems debatable for a number of reasons. On the first point, we must admit that in the Directive there is nothing saying that the protection of TPMs does not apply to game consoles; but neither there is something suggesting that it does. Nothing in the directive says that the protection of TPMs applies to garage doors or to printer cartridges. Does this suggest that the protection of TPMs can be extended to these items too? Essentially, to the question: "can TPMs be applied to portable equipment or consoles?" the Court replied: "why not?"

Secondly, and most importantly, the Court argues -citing the Opinion of the AG- that the concept of technological protection measures is defined broadly in the Directive, as "application of an access control or protection process, such as encryption, scrambling or other transformation of the work or other subject-matter or a copy control mechanism." ${ }^{11}$ The argument of the broad interpretation of TPMs seems flawed for at least three reasons. First, the number of examples provided in the text of the Directive (access control, copy control, encryption, scrambling) suggests the objective to define the concept (e.g. putting boundaries to it) rather than leaving it open to interpretation. Second, the examples provided suggest the implementation of technological measures on the object of copyright protection, or at the very most, on the physical carrier hosting it (CD, DVD, game cartridge, etc.). Crucially, interoperability is normally facilitated by TPMs implemented only on the disk or cartridge.

Third, and most importantly, the Court underpins its broad interpretation of the concept of TPMs on the general principle of the "high level of protection" for right holders, provided by the Copyright Directive. ${ }^{12}$ However, the high protection of the Copyright Directive refers to the exclusive rights of the owner (Reproduction, Communication and Distribution), which in fact by express wording of the recitals of the directive must be construed broadly (recitals 21 to 25). In short, when the Directive requires a broad protection, it says so; and it did not say so regarding TPMs. Technological protection measures are not entitled to a strong protection because they are not rights of the owner, but mere technical tools to enforce them. ${ }^{13}$

Moreover, not all usage restrictions are protected by the EU Copyright Directive. TPMs are allowed to stop only uses related to unauthorised reproduction, communication and distribution of the work. Access to the work is not a supplementary right of the owner, and therefore cannot be lawfully

\footnotetext{
${ }^{10}$ Case C-355/12 Judgement, 26.

${ }^{11}$ Copyright Directive, Article 6.3.

${ }^{12}$ Copyright Directive, Recitals 4 and 9.

${ }^{13}$ M. Favale, 'The Right of Access in Digital Copyright: Right of the Owner or Right of the User?', 15(1) The Journal of World Intellectual Property, (2012) 1-25, at 11.
} 
controlled by TPMs. ${ }^{14}$ This principle was confirmed by both the AG and the European judges in their respective documents. They both stated that TPMs cannot protect other than the rights recognised by the Copyright Directive, in Articles 2, 3 and 4; and in fact, copyright owners normally implement the anti-copy device on the digital work (or the disk including it) so that these items can be rendered but not reproduced. Instead, the device implemented by Nintendo forbids any use, including access, to non-proprietary videogames.

Finally, it has been mentioned in the documents of the case that game consoles are not all purpose devices, like computers, phones, and tablets, in order to suggest that they are not bound to allow the functioning of non-proprietary products. However, there are other mono-purpose devices, such as CD players, DVD players, internet platforms (such as iTunes), that do allow playing non-proprietary material on their devices. They can do that thanks to interoperability standards, which allow on the one hand the use of homebrew material, and on the other hand the correct functioning of competition.

In essence, as correctly sensed (but not developed) by AG Sharpston, the importance of allowing legitimate behaviours through interoperability, albeit not strongly protected by the Copyright Directive, allows legitimate behaviours under copyright law, and it is therefore essential.

\title{
The second question
}

The concerns of the Italian Court however did not stop with the first question. The second question addressed by the Milan District Court to the European judges states:

\begin{abstract}
Should it be necessary to consider whether or not the use of a product or component whose purpose is to circumvent a technological protection measure predominates over other commercially important purposes or uses, may Article 6 of Directive 2001/29/EC be interpreted, including in the light of recital 48 in the preamble thereto, as meaning that the national court must adopt criteria in assessing that question which give prominence to the particular intended use attributed by the right holder to the product in which the protected content is inserted or, in the alternative or in addition, criteria of a quantative nature relating to the extent of the uses under comparison, or criteria of a qualitative nature, that is, relating to the nature and importance of the uses themselves?
\end{abstract}

At the outset, I need to agree with AG Sharpston that a little more clarity would have been useful. ${ }^{15}$ However, in essence the Tribunale di Milano asks what importance has to be reserved to the uses of the circumventing device when assessing whether TPMs deserve or not protection under the Directive. To this end, the District Court specifies that a number of considerations are possible. First, one can take into account the intended use attributed by the manufacturer of the protected device. Second, a quantitative assessment could verify the volume of infringing behaviours compared to legitimate behaviours. Third and finally, qualitative arguments could assess the relative importance

\footnotetext{
${ }^{14}$ Ibid, at 16.

${ }^{15}$ Case C-355/12 Opinion, 39.
} 
of either behaviour. Which one of these arguments, if any, a national court has to take into account when deciding whether TPMs are protectable?

The answer of AG Sharpston starts with a step back: first of all, in order to determine whether TPMs deserve protection under the directive, according to its text, they have to be "effective" and they have to protect the rights of the copyright owner, which are Reproduction (Article 2 Copyright Directive), Communication (Article 3 Copyright Directive) and Distribution (Article 4 Copyright Directive). As stated by the Commission in fact, the Directive "does not seek to create any rights other than those specified in Articles 2, 3 and 4 ". ${ }^{16}$ Then, the AG shares with the Commission the view that a proportionality test has to be applied (according to Recital 48 of the Directive) assessing : 1) whether a TPM pursue a legitimate aim; 2) whether the TPM is suitable to achieve that aim; and 3) whether it does not go beyond what it is necessary to achieve that aim. ${ }^{17}$ The latter point implies that legitimate behaviours can be stopped by TPMs only if there is no other way to protect effectively the rights of the owner.

The intended use of a device attributed by the manufacturer is considered irrelevant by both the Advocate General ${ }^{18}$ and the Court. The key issue seems to be instead the "the extent, the importance and the nature of the uses" (for AG Sharpston) ${ }^{19}$ or "the scope, the nature and the importance" of the uses (for the Court). ${ }^{20}$ The extent of the infringing uses according to the Court has to be assessed depending on the volume of infringing behaviours compared to the volume of legitimate behaviours (quantitative assessment).

The analysis of the Court initially seems to follow by and large the Opinion of AG Sharpston. The judges acknowledge that only the rights mentioned in the directive deserve copyright protection ${ }^{21}$ and it refers to the proportionality principle which requires that protectable TPMs do not prohibit devices or activities that have a commercially significant purpose other than circumventing copyright protection (here citing Recital 48 of the Copyright Directive). However, the Court suggests that the national court should assess how often the allegedly circumventing devices are used for infringing behaviours and how often they are used for legitimate aims. Moreover, instead of carrying out the three-steps test recommended by AG Sharpston, the Court suggests to ascertain whether TPMs different from those installed on the game console "could cause less interference" with the activities of third parties [...] while still providing comparable protection to the right holder's rights". This assessment, according to the Court, has to be effected by keeping into account 1 ) the relative costs

\footnotetext{
${ }^{16}$ Case C-355/12 Opinion, 72.

${ }^{17}$ Case C-355/12 Opinion, 55.

${ }^{18}$ Case C-355/12 Opinion, 79.

${ }^{19}$ Case C-355/12 Opinion, 41.

${ }^{20}$ Case C-355/12 Judgement, 20

${ }^{21}$ Case C-355/12 Judgement, 31.
} 
of the compared measures;2) their relative effectiveness; 3 ) "technological and practical aspects of their implementation".22

Thus, summing up, the legitimate aim requires that the right holders seek protection of their legitimate rights (reproduction, communication and distribution); the suitability of the aim is related to the effectiveness of the measures (which is normally assumed); and the proportionality would include an assessment of the behaviour of videogames users and of the current state of technology to verify whether another TPM solution would be less intrusive against legitimate uses.

To this end, the burden of the proof shifted on the copyright holder is rather heavy: the right holders have to demonstrate that pirates prevail over legitimate users of their products, and that their TPMs are the only possible solution (keeping into account costs, technology and effectiveness) to protect copyright without hindering third parties products (interoperability). At first blush, this seems to require some substantial investment in social science and information technology research.

The question of a qualitative assessment between the importance of the protection against unauthorized behaviours and the importance of the protection of legitimate behaviours remain substantially unanswered. AG Sharpston indeed senses the possibility, hidden in the formulation of the question by the national court, that "the importance of allowing Nintendo's consoles to be used for purposes which did not infringe any exclusive rights might outweigh the importance of preventing or restricting unauthorised acts". ${ }^{23}$ She admits that in some cases may be important that TPM do not interfere with "user's rights to carry out acts which require no authorization". ${ }^{24}$ However, she adds, since the latter are not fundamental rights, these qualitative criteria should be seen in light of the quantitative criteria assessing the extent and the frequency of the infringing behaviour. ${ }^{25}$

Thus since "user's rights" are not "fundamental rights", they do not deserve to be protected, unless the volume of these rights prevails over the volume of infringing behaviours. If the AG meant that these rights have to be balanced against fundamental rights (copyright) and therefore they deserve comparatively less protection, she should have discussed this point more in depth. Useful considerations on this issue would include the extent to which copyright is a fundamental right, ${ }^{26}$ and why the European Court of Justice has in the past preferred to protect fundamental rights against copyright. ${ }^{27}$

\footnotetext{
${ }^{22}$ Case C-355/12 Judgement, 38.

${ }^{23}$ Case C-355/12 Opinion, 76.

${ }^{24}$ Case C-355/12 Opinion, par 78.

${ }^{25}$ Case C-355/12 Opinion, 78

${ }^{26}$ The nature of copyright as fundamental right is problematic. See M. Favale, 'The Right of Access in Digital Copyright: Right of the Owner or Right of the User?', 15(1) The Journal of World Intellectual Property, (2012) 1-25, at 13. Also P. L. C. Torremans, 'Copyright as a Human Right', in P. L. C. Torremans (ed.), Copyright and Human Rights. (The Hague: Kluwer Law International 2004) pp. 1-20, at 9

${ }^{27}$ C-275/06 Promusicae [2008] ECR I-00271; C-461/10 Bonnier Audio (not yet published on ECR); C-70/10 Scarlet Extended (not yet published on ECR).
} 


\section{The competition issue}

AG Sharpston stated at the outset of her discussion that this case involved competition issues. In fact, from the summary of the factual situation of the case we know that the main defensive argument of PC Box is a competition argument. The Tuscan Undertaking argues that the real intention of Nintendo is to stop competitors from using non-proprietary videogames on its consoles. Moreover, the reference to interoperability obviously recalls competition issues, as landmark cases show (see Microsoft ${ }^{28}$ ).

However, the AG stated that since unfortunately the national court failed to incorporate a question on competition in the reference for a preliminary ruling, she will not discuss it. AG Sharpston is well aware of the potential impact of this issue, as she mentions in her Opinion the importance to ascertain whether the aims of Nintendo are really legitimate. She writes: "If, on the other hand, the national court were to find that Nintendo was pursuing in addition any other aim not justified in the context of that directive, the extent to which the nature of the technological measures was determined by the latter aim would have to be taken into account when examining whether those measures were suitable to achieve the legitimate aim of preventing or restricting unauthorized acts"29.

Legitimate aims, as we have seen above, only involve the protection from unauthorized Reproduction, Communication and Distribution of works protected by copyright. If the implementation of TPMs is determined not by the protection of these rights but by illegitimate aims (which certainly include unfair competition strategies) they do not qualify for legal protection. However, the extent and nature of these illegitimate aims are for national courts to be ascertained.

The judgment of the Court, in turn, ignores altogether any reference to competition issues. However, we have instances of previous case-law where, albeit competition issues were not explicitly included in the preliminary reference, the Court interpreted copyright law in the context of economic considerations (the stability of the Internal Market), as for example in Usedsoft. ${ }^{30}$ We cannot discard the relevance of this example on the basis that it refers to software, also because the question of the inapplicability of the Software Directive to videogames has not been exhaustively discussed in Nintendo.

\footnotetext{
${ }^{28}$ Case 37792 Microsoft, available at < http://ec.europa.eu/competition/elojade/isef/case_details.cfm?proc_code=1_37792>

${ }^{29}$ Case C-355/12 Opinion par 59.

${ }^{30}$ Case C- 128/11 UsedSoft (not yet published on ECR), Judgement, at 62: "the objective of the principle of the exhaustion of the right of distribution of works protected by copyright is, in order to avoid partitioning of markets, to limit restrictions of the distribution of those works [...]". Although Usedsoft is related to software, the exhaustion principle is provided by both the Copyright Directive and the Software Directive, and its rationale (protecting competition in the Internal Market) is the same.
} 


\section{The Software issue}

After declaring that videogames deserve copyright protection because they are the author's intellectual creation, ${ }^{31}$ the Court excludes the application of Directive 2009/24 (Software Directive). ${ }^{32}$ The question is dismissed in one paragraph, with the argument that 1) Directive 2009/24 protects only computer programs; 2 ) videogames consist of software, graphic and sound; 3) graphic and sound are protected by copyright (Directive 29/2001) together with the whole work.

More specifically, the judges say: "In so far as the parts of a videogame, in this case, the graphic and sound elements, are part of its originality, they are protected, together with the entire work, by copyright in the context of the system established by Directive 2001/29". However, by admission of the same Court videogames are also consisting in software, and therefore the Software Directive should be also applicable. This would make a world of difference to the case at hand, because the Software Directive, unlike the Copyright Directive, requires the interoperability of software. As general principles of law require, each ruling should be based on a clear motivation (well, or a motivation at least).

In Nintendo the Court decided that the Software Directive is not applicable to videogames, without a motivation. However, AG Sharpston makes reference to a pending case before the Court (C-458/13 Grund). In this case, according to the AG, the applicability of the Software Directive to videogames will be thoroughly discussed and motivated. Unfortunately, on the $7^{\text {th }}$ of May 2014 the President of the Court issued a Court Order which radiates case C-458/13 (Grund) from the Court Registry. This case will therefore never be discussed, and the application of the Software Directive to videogames will never be argued, or even less motivated. This is at least obnoxious, if we consider that other cases involving Nintendo and its competitors have been discussed before other jurisdictions entirely on the basis of software regulations (see for example Atari $v$ Nintendo ${ }^{33}$ ).

On this point, therefore, the ruling of Nintendo raises serious issues of credibility. Videogames, the Court says (and everybody agrees) consist of software, graphics and sound. If graphics and sound (and the software source code) deserve copyright protection, the software "part" of videogames deserves "software protection" and it has to comply with the relevant exceptions to this protection, in particular the requirement for interoperability. ${ }^{34}$ The Nintendo case would have had a totally

\footnotetext{
${ }^{31}$ Case C-5/08 Infopaq International [2009] ECR I-6569, paragraph 35.

32 Directive 2009/24/EC of the European Parliament and of the Council of 23 April 2009 on the legal protection of computer programs OJ L 111/16

${ }^{33}$ Atari Games Corp. v. Nintendo of America Inc. U.S. Court of Appeals, Federal Circuit. September 10,1992. 975 F.2d 832, 24 USPQ2d 1015.

${ }^{34}$ Software Directive, Article 6.1.
} 
different outcome, if the judges had decided to apply the Software Directive. But they decided otherwise, without saying why. ${ }^{35}$

\section{Conclusion}

This was the first decision that the European Court of Justice has ever delivered on the important issue of Digital Rights Management, of which the technological protection measures are a crucial component.

The question of the protection of TPMs implemented on hardware devices, unprecedented in European copyright, would deserve to be discussed and motivated rather more rigorously than with a simple "why not?". What are the implications of this decision on other devices which do not contain or host copyright works, but are able to activate digital carriers that contain or host copyright works? Would the European Court for example support the implementation of TPMs on CD or DVD players if statistical evidence is produced suggesting that most users own more pirated disks than legally purchased or personal disks?

Moreover, the extremely important question of the applicability of the Software Directive to videogames needs to be rigorously examined and legally motivated. In this case the issues of software and the issue of competition have not been properly addressed, and the parties should seek further deliberation on these matters before the competent authorities.

The decision of the Court and the analysis of the AG contain few extremely laudable points, such as the principle that TPMs cannot protect but the exclusive rights of the owners and the principle that protectable TPMs have to pass a proportionality test. Moreover, the conditions imposed by the Court for the legal protection of TPMs, the inexistence of less intrusive but equally effective TPMs, and the prevalence of infringing behaviour over legitimate behaviour, are so difficult to prove in practice that this might disrupt the implementation of DRM in practice (to the joy of users' rights organizations). However, the above observations suggest that the implications of such decision can go well beyond the intentions of the European judges. These implications can adversely affect users' "not fundamental" rights and competition in the Internal Market. It is therefore a little too early to be overly pleased with this decision.

\footnotetext{
${ }^{35}$ We are convinced that it is perfectly possible to protect software, which constitutes the stuff and fabric of a videogame, with software regulation while protecting the graphics and sounds with copyright. In fact, the European Court has already clearly stated this principle.C-393/09 - Bezpečnostní softwarová asociace [2007] ECR I- 4887. Judgement, 59.1 "A graphic user interface is not a form of expression of a computer program [...] and cannot be protected by copyright as a computer program under that directive. Nevertheless, such an interface can be protected by copyright as a work by Directive 2001/29/EC [...] if that interface is its author's own intellectual creation."
} 